\title{
Barriers and facilitators to participating in cardiac rehabilitation and physical activity in a remote and rural population: A cross-sectional survey
}

\author{
Emma J. Foster ${ }^{1}$, Sarah-Anne Munoz ${ }^{2}$, Daniel Crabtree ${ }^{2}$, \\ Stephen J. Leslie ${ }^{2,3}$, Trish Gorely ${ }^{2}$
}

${ }^{1}$ School of Medicine, Medical Sciences and Nutrition, University of Aberdeen, United Kingdom ${ }^{2}$ University of the Highlands and Islands, Centre for Health Science, Inverness, United Kingdom ${ }^{3}$ Cardiac Unit, Raigmore Hospital, Inverness, United Kingdom

\begin{abstract}
Background: Cardiac disease requires ongoing active management which may include attendance at formal cardiac rehabilitation (CR) and increased physical activity (PA). However, uptake rates are sub-optimal. This study aimed to identify factors associated with attendance at CR and PA in a rural Scottish population.

Methods: A cross-sectional postal survey assessing factors potentially associated with attending $C R$ and participating in PA. Data were also collected from hospital electronic medical records. Binary logistic and ordinal regressions were used to identify barriers and facilitators to participation.

Results: The cohort consisted of 840 participants referred to the CR department of a regional Scottish hospital. After applying the inclusion/exclusion criteria, 567 patients were sent a questionnaire. The number of returned questionnaires was 295 (52.0\%). Responders were predominantly male (75.9\%), with a mean age of 68.7 years. At the multivariate level, the only factor associated with CR attendance was a lack of perceived need (odds ratio [OR] 0.02, 95\% confidence interval [CI] 0.01-0.06). Analyses of $P A$ associations identified self-efficacy as the only significant facilitator (OR 1.29, 95\% CI 1.05-1.59), and a lack of willpower as the only barrier (OR 0.42, 95\% CI 0.18-0.97). Other factors were linked to $C R$ attendance and $P A$ at a univariate level only.

Conclusions: This study characterised CR and PA participation, and explored demographic, medical, and psychological factors associated with both activities - with the most important being perceived need, self-efficacy and willpower. These findings may be beneficial in clinical practice by targeting these factors to increase CR attendance and PA levels. (Cardiol J 2021; 28, 5: 697-706)
\end{abstract}

Key words: cardiac rehabilitation, physical activity, barriers, facilitators, rural

\section{Introduction}

Heart disease is a leading cause of mortality worldwide [1]. Cardiac rehabilitation (CR) aims to reduce morbidity and mortality from heart disease by targeting modifiable risk factors, such as obesity, smoking and lack of exercise [2]. The most important element of $\mathrm{CR}$, in terms of reducing cardiovascular mortality, hospital admissions, and increasing health-related quality of life, is exercise (or physical activity [PA]) [3].

It is recommended that all adults should achieve a weekly minimum of 150 min of moderateintensity PA, or 75 min of vigorous-intensity PA, in bouts of $10 \mathrm{~min}$ or more [4]. Despite the proven benefits and endorsement in national guidelines,

Address for correspondence: Dr. Trish Gorely, University of the Highlands and Islands, Centre for Health Science, Old Perth Road, Inverness, IV2 3JH, United Kingdom, tel: 01463 279811, e-mail: trish.gorely@uhi.ac.uk

Received: 23.04.2019 Accepted: 4.07.2019 Early publication date: 24.09.2019

A draft of this work was presented as an oral abstract at the BACPR annual conference on the $5^{\text {th }}$ of October 2018.

This article is available in open access under Creative Common Attribution-Non-Commercial-No Derivatives 4.0 International (CC BY-NC-ND 4.0) license, allowing to download articles and share them with others as long as they credit the authors and the publisher, but without permission to change them in any way or use them commercially. 
in 2012 it was shown that $47 \%$ of adult women and $37 \%$ of adult men in Scotland were not achieving these recommendations [5]. In addition, CR uptake remains suboptimal, with only $51 \%$ of eligible patients attending in England, Wales and Northern Ireland [6].

Factors associated with poor CR attendance include: age, gender, lack of knowledge, cost, lack of transport, self-efficacy, motivation, and social support [7, 8]. Distance from classes may be particularly important in remote rural populations $[9,10]$. Factors associated with lower PA (distinct from CR attendance) include: poor health, lack of time, knowledge or access to facilities, costs, gender, motivation and self-efficacy, to name a few [11]. These factors remain relatively understudied in rural areas and the paucity of evidence in such populations may have particular implications for Scotland, where over $20 \%$ of the country is classed as remote or rural $[6,12]$.

This study aimed to explore factors influencing participation in CR and PA after a cardiac event in a remote and rural Scottish population to identify potential targets for future interventions to improve participation rates.

\section{Methods}

\section{Design}

The study employed a cross-sectional survey design.

\section{Participants}

Consecutive patients referred for standard CR classes at a regional hospital in the North of Scotland from May 2016 to May 2017 were included, the catchment area of this hospital being over $30,000 \mathrm{~km}^{2}$ and including several CR sites. Patients were referred to $\mathrm{CR}$ following an acute coronary syndrome (myocardial infarction or unstable angina), angina, heart failure, post-cardiac surgery (valves, transplantation or coronary artery bypass grafting $[\mathrm{CABG}])$, percutaneous coronary intervention (PCI), cardiac device implantation, adult congenital heart disease, out-of-hospital cardiac arrest, or a step-change in their cardiac condition. Exclusion criteria were: previous referrals of the same patient, not resident in catchment area, aged less than 18 , non-cardiac or unclear diagnosis, or if $\mathrm{CR}, \mathrm{PA}$ or questionnaire completion was deemed inappropriate for the specific patient (e.g. frailty, life-limiting or distressing illness, severe dementia or other severe psychiatric condition). The latest referral of the participant was used if the patient had been invited to $\mathrm{CR}$ on more than one occasion.

\section{Instruments}

The survey contained 4 sections, which combined several questionnaires, and respectively collected data regarding: demographics; quality of life; CR; and PA. All individual questionnaires have previously been validated and demonstrate adequate psychometric properties.

The demographic section included questions about age, gender, working status and occupation, smoking status, education, home occupants, feelings of loneliness, and transport access.

Quality of life was assessed using the European Quality of Life 5 Dimensions (EQ-5D-5L) instrument and the European Quality of Life Visual Analogue Scale (EQ-VAS), with permission for use being obtained $[13,14]$. A single index value of health state ( 0 being low, to 1 being higher) was generated from the EQ-5D-5L, using the Devlin et al. [14] value set. The EQ-VAS asks participants to rate their overall health out of 100 ( 0 being "the worst health imaginable", and 100 being "the best").

Cardiac rehabilitation experience was assessed by initially asking 3 questions: were they invited to CR; did they attend all, some or none of the classes; and whether they had ever previously attended CR. Barriers and facilitators to attending CR were assessed using the Cardiac Rehabilitation Barriers Scale $\left({ }^{\circ} \mathrm{CRBS}\right.$, permission for use obtained) [15]. The ${ }^{\circ} \mathrm{CRBS}$ (CCRBS: [15]) comprises 21 items and uses a 5-point Likert scale instrument (strongly disagree to strongly agree) to assess potential barriers in 4 key areas: perceived need/health care factors (e.g. "I don't need cardiac rehab", "my doctor did not feel it was necessary"); logistical factors (e.g. distance, cost); work/time conflicts, and comorbidities/functional status (e.g. "I am too old", "I don't have the energy") [15].

Physical activity was assessed using the International Physical Activity Questionnaire (IPAQ) short version [16]. Participants were grouped into low, moderate or high PA levels based on the IPAQ group scoring guideline [17]. Barriers to PA were assessed by the Barriers to Being Active Quiz, which comprises 21 statements, measuring barriers over 7 areas: social influences, fear of injury, and lack of; skill, energy, willpower, time, and resources [18]. The scoring of this questionnaire produces a binary predictor - barrier present or absent.

Social support was assessed with the Social Support and Exercise Survey [19]. Participants rated how often family and friends participated in certain activities regarding PA, with higher scores indicating more social support for exercise. PA self- 


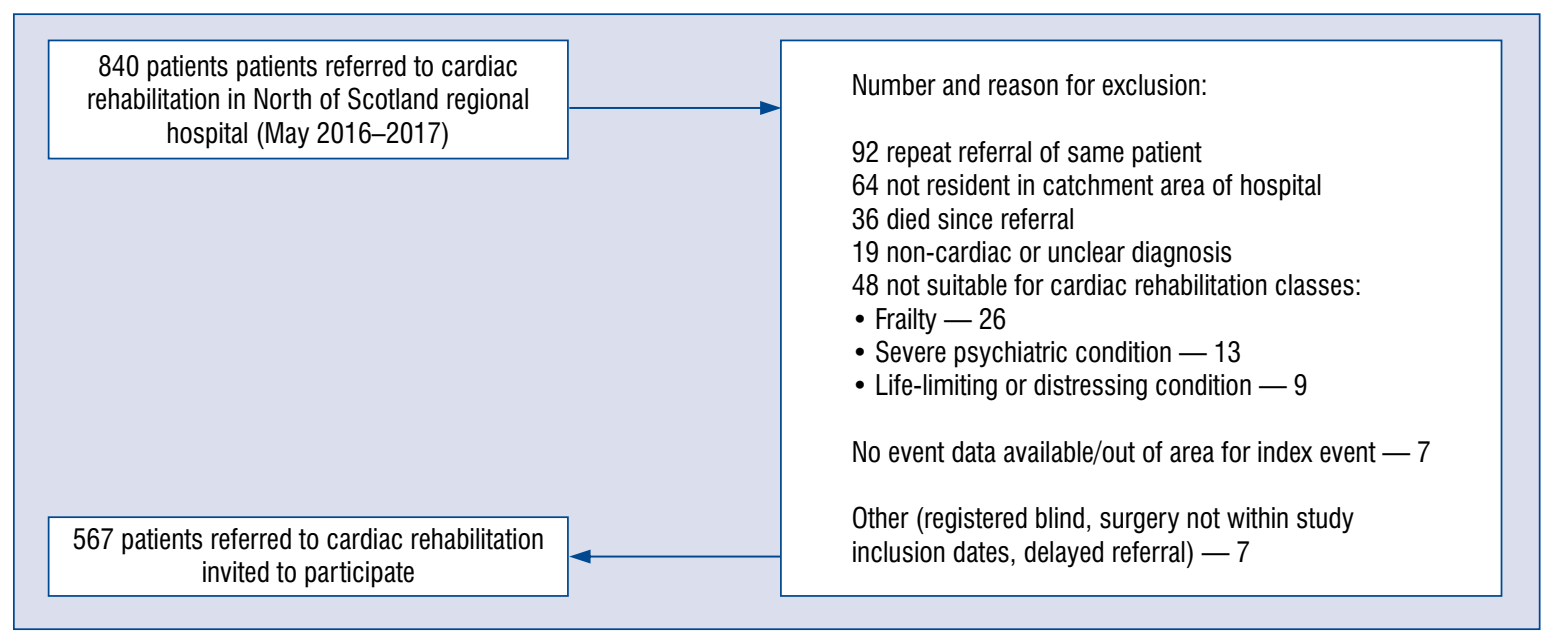

Figure 1. Displaying the process of participant exclusion.

efficacy was measured using a 12 -item instrument, asking participants to rate their confidence in their ability to be active in various circumstances [20]. The items were then scored into 3 themes, selfefficacy for: overcoming barriers to being active, completing the activity itself, and scheduling time to be active. A higher score indicates higher PA self-efficacy in that subscale. Motivation for PA was assessed using the intrinsic, extrinsic and amotivation subscales from the Behavioural Regulation in Exercise Questionnaire [21, 22].

\section{Procedures}

The cohort was screened using electronic hospital medical records and participants identified who satisfied the inclusion/exclusion criteria. A subject specialist (cardiologist) adjudicated any uncertainties regarding patient inclusion. Identified participants were then sent a study pack containing a personalised cover letter, patient information sheet, consent form, the questionnaire, and a stamped addressed return envelope. A reminder pack was sent after 2-3 weeks to non-responders, with data collection being terminated after 6 weeks. Ethical approval was obtained from the Bromley Research Ethics Committee (study reference number 17/LO/1389, project number 231385).

The diagnosis, management, and co-morbidity data reported at the time of the index event was collected from electronic hospital medical records. Participant postcodes were used to assess rurality and socioeconomic status using the Scottish Government 6-fold Urban Rural Classification 2013/14, and the Scottish Index of Multiple Deprivation (SIMD) 2016 quintiles, respectively [12, 23].

\section{Statistical analysis}

All data were anonymised, then entered and analysed using SPSS (version 24, IBM Corp., Armonk, NY, USA). The analysis was conducted in two stages. In step one, each independent variable was examined in a univariate analysis using a variety of descriptive statistics, $\chi^{2}$, independent $t$-tests, and ANOVA approaches to explore group differences.

In step two, all factors associated with the outcome (CR attendance or PA level) at the $10 \%$ significance level were included within a multivariate analysis using binary and ordinal logistic regressions. Binary logistic regression was used to identify factors associated with attending CR (attended all classes vs no classes). Participants who reported attending "some" classes $(\mathrm{n}=49$, $17.3 \%$ ) were excluded as it was not possible to distinguish the degree of attendance and therefore their responses could have confounded the results. A similar approach was employed to identify associations with PA, however, ordinal logistic regression was used, due to the presence of three groups.

\section{Results}

\section{Study cohort}

The initial cohort was composed of 840 individuals referred to CR. After applying inclusion/ exclusion criteria, 567 individuals were invited to participate. This process, and participant exclusion rationale, is summarised in Figure 1.

\section{Sample characteristics}

Of the 567 patients, 295 (52\%) returned a questionnaire. The mean age of responders was 
$68.7 \pm 10.5$ years (range 33-90), with $224(75.9 \%)$ men. Compared to non-responders, responders were older (non-responders mean age 65.0 vs. responders $68.7, \mathrm{p}<0.001$ ), had a higher proportion of men $(75.9 \%$ in responders vs. $66.9 \%$ non-responders, $\mathrm{p}=0.022$ ) and tended to be from more affluent areas $(p=0.001)$. There were no significant differences between responders and non-responders in terms of rurality, diagnosis, management, or co-morbid status.

\section{Barriers to attending cardiac rehabilitation}

Table 1 compares the characteristics of responders who attended $(\mathrm{n}=101)$ and did not attend $(\mathrm{n}=133) \mathrm{CR}$, and displays the multivariate analysis. Attenders were less likely to be smokers $(p=0.023)$, were from more affluent areas $(p=0.041)$, from less rural areas $(p=0.026)$, and have fewer morbidities on average $(\mathrm{p}=0.031)$. Attenders scored lower than non-attenders on all barrier's subscales $(\mathrm{p}<0.001)$.

Factors with univariate significance at the $10 \%$ level $(p \leq 0.1)$ were entered into the final multivariate model. The model was significant $(\mathrm{p}<0.001$; Nagelkerke $R^{2}=0.690$ ). Lack of perceived need for CR was the only significant factor, and was associated with a 50 -fold reduction in attendance (odds ratio [OR] $0.02,95 \%$ confidence interval [CI] 0.01-0.06, p < 0.001).

\section{Barriers to physical activity}

Table 2 compares the characteristics of participants when grouped by PA levels according to the IPAQ, and shows the multivariate analysis. Compared to low active participants, higher active patients were more likely to be younger $(\mathrm{p}=0.008)$, nonsmokers $(p=0.015)$, in employment $(p=0.033)$, living with a spouse or partner $(\mathrm{p}=0.03)$, less lonely $(\mathrm{p}=0.049)$ and had access to a bicycle $(p=0.006)$. They were also more likely to report higher quality of life $(\mathrm{p}<0.001)$ and have less comorbidities on average $(\mathrm{p}<0.001)$. Higher active patients also reported higher social support from family and friends, self-efficacy and intrinsic motivation to be active. Conversely, increased co-morbidity, lack of positive social influence, lack of will power, and lack of skill were associated with lower levels of activity. CR attendance for the index event was also associated with higher levels of PA $(\mathrm{p}=0.009)$.

Factors with univariate significance at the $10 \%$ level were entered into a multivariate model, which was significant $(\mathrm{p}=0.001$, test of parallel lines $\mathrm{p}=0.074$; the Pearson $\chi^{2}$ statistic goodnessof-fit $\mathrm{p}=0.236$, Nagelkerke $\mathrm{R}^{2}=0.316$ ). Two significant predictors of PA emerged: self-efficacy for overcoming barriers to being active (OR 1.29, 95\% CI 1.05-1.59, $\mathrm{p}=0.016$ ), which was associated with higher activity levels (a facilitator); and lack of willpower (OR 0.42, 95\% CI 0.18-0.97, $\mathrm{p}=0.043)$, which was associated with lower levels of activity (a barrier).

\section{Discussion}

This study demonstrated that perceived need for CR, and self-efficacy for overcoming barriers and willpower for PA were significant predictors of participation. These are important findings, suggesting factors that could be targeted with interventions in clinical practice to address low participation in cardiac patients.

\section{Cardiac rehabilitation}

Cardiac rehabilitation participation rate in this population was found to be $53.0 \%$, with a completion rate of $67.3 \%$. This is broadly consistent with United Kingdom (UK) national averages (51\% and $77 \%$ respectively in 2017 [6]). Within this UK audit [6], differences in attendance were reported by diagnostic and management subgroups, such as increased uptake in PCI and CABG patients, however, no such differences were identified in this study. This may be due to differences in diagnostic and management definitions, sample differences (e.g., the audit sample was much larger), or modes of CR delivery examined (only traditional exercise class CR was investigated in this study).

Perceived need was identified as the single most important factor associated with CR nonattendance. This finding is consistent with previous studies citing perceived need, or the items used to score this subscale, as significant barriers [10, 24, 25]. Perceived need consists of patient and healthcare provider factors. The healthcare factors include: lengthy referral processes, no contact from the department, not knowing about $\mathrm{CR}$, and the perception that their doctor did not think CR was necessary [15]. These healthcare factors provide potential targets for service improvement, and enhancing these aspects of the programme may exert a positive effect on patient understanding of $\mathrm{CR}$ necessity, and therefore increase attendance. For example, previous research has suggested that the "strength of referral" (how strongly physicians advocate CR) among other physician-related factors are key in uptake, and may prove a vital intervention target for the service [26, 27]. Personal factors associated with perceived need (e.g. "I don't 
Table 1. Characteristics of attenders compared with non-attenders and factors associated with attendance.

\begin{tabular}{|c|c|c|c|c|c|}
\hline & \multirow{2}{*}{$\begin{array}{l}\text { Non-attender } \\
\quad(n=133)\end{array}$} & \multirow{2}{*}{$\begin{array}{l}\text { Attender } \\
(n=101)\end{array}$} & \multirow[t]{2}{*}{$\mathbf{P}$} & \multicolumn{2}{|c|}{ Multivariate $^{+}$} \\
\hline & & & & OR (95\% CI) & $\mathbf{P}$ \\
\hline Age, range; $n=234$ & $68.9 \pm 11.5,33-90$ & $68.6 \pm 9.8,37-86$ & 0.793 & - & - \\
\hline Men; $n=234$ & $99(74.4 \%)$ & $79(78.2 \%)$ & 0.605 & - & - \\
\hline \multicolumn{6}{|l|}{$\begin{array}{l}\text { Scottish index of multiple depriva- } \\
\text { tion score quintile; } n=232 \text { : }\end{array}$} \\
\hline 1 or 2 (most deprived) & $28(21.1 \%)$ & $12(12.1 \%)$ & 0.041 & 1.00 & \\
\hline 3 & $47(35.3 \%)$ & $28(28.3 \%)$ & & $1.51(0.37-6.09)$ & 0.566 \\
\hline 4 or 5 (least deprived) & $58(43.6 \%)$ & $59(59.6 \%)$ & & $2.89(0.82-10.25)$ & 0.100 \\
\hline \multicolumn{6}{|l|}{$\begin{array}{l}\text { Scottish urban rural } 6 \text {-fold } \\
\text { classification; } n=230 \text { : }\end{array}$} \\
\hline Other urban area & $24(18.3 \%)$ & $35(35.4 \%)$ & 0.026 & 1.00 & \\
\hline Remote small town & $29(22.1 \%)$ & $16(16.2 \%)$ & & $0.72(0.19-2.75)$ & 0.628 \\
\hline Accessible rural & $14(10.7 \%)$ & $6(6.1 \%)$ & & $0.25(0.05-1.39)$ & 0.113 \\
\hline Remote rural & $64(48.9 \%)$ & $42(42.4 \%)$ & & $0.63(0.20-1.99)$ & 0.428 \\
\hline Working (full or part-time); $\mathrm{n}=228$ & $43(32.8 \%)$ & $28(28.9 \%)$ & 0.622 & - & - \\
\hline $\begin{array}{l}\text { Feelings of loneliness } \\
\text { (sometimes or often); } n=229 \\
\text { Home occupants; } n=230 \text { : }\end{array}$ & $50(37.9 \%)$ & $41(42.3 \%)$ & 0.593 & - & - \\
\hline Alone & $32(24.2 \%)$ & $18(18.4 \%)$ & 0.108 & - & - \\
\hline Spouse/partner & $91(68.9 \%)$ & $78(79.6 \%)$ & & - & - \\
\hline Other (family/friends/pets) & $9(6.8 \%)$ & $2(2.0 \%)$ & & - & - \\
\hline \multicolumn{6}{|l|}{ Smoking; $\mathrm{n}=231$ : } \\
\hline Never & $50(37.9 \%)$ & $42(42.4 \%)$ & 0.023 & $\hat{\imath}$ & $\hat{\imath}$ \\
\hline Ex-smoker & $62(47.0 \%)$ & $53(53.5 \%)$ & & $\hat{\imath}$ & $\hat{\imath}$ \\
\hline Smoker & $20(15.2 \%)$ & $4(4.0 \%)$ & & $\wedge$ & $\wedge$ \\
\hline \multicolumn{6}{|l|}{ Highest level of education; $n=229$ : } \\
\hline School & $67(51.1 \%)$ & $36(36.7 \%)$ & & 1.00 & \\
\hline College & $37(28.2 \%)$ & $35(35.7 \%)$ & 0.094 & $0.80(0.28-2.32)$ & 0.686 \\
\hline University & $27(20.6 \%)$ & $27(27.6 \%)$ & & $1.42(0.42-4.81)$ & 0.575 \\
\hline \multicolumn{6}{|l|}{ Diagnosis; $\mathrm{n}=234$ : } \\
\hline Non-ST elevation MI & $41(30.8 \%)$ & $36(35.6 \%)$ & 0.714 & - & - \\
\hline ST elevation $\mathrm{MI}$ & $35(26.3 \%)$ & $19(18.8 \%)$ & & - & - \\
\hline Unstable angina & $12(9.0 \%)$ & $11(10.9 \%)$ & & - & - \\
\hline Stable angina & $26(19.5 \%)$ & $19(18.8 \%)$ & & - & - \\
\hline $\begin{array}{l}\text { Other (HF, arrhythmia or } \\
\text { structural cardiac disease) }\end{array}$ & $19(14.3 \%)$ & $16(15.8 \%)$ & & - & - \\
\hline \multicolumn{6}{|l|}{ Management; $\mathrm{n}=234$ : } \\
\hline Medical & $25(18.8 \%)$ & $16(15.8 \%)$ & 0.291 & - & - \\
\hline Percutaneous coronary intervention & $89(66.9 \%)$ & $63(62.4 \%)$ & & - & - \\
\hline Surgical & $18(13.5 \%)$ & $18(17.8 \%)$ & & - & - \\
\hline Cardiac device & $1(0.8 \%)$ & $4(4.0 \%)$ & & - & - \\
\hline \multicolumn{6}{|l|}{ Co-morbidities; $\mathrm{n}=234$ : } \\
\hline Number of co-morbidities, range & $2.8 \pm 2.1,0-13$ & $2.3 \pm 1.6,0-8$ & 0.031 & $0.77(0.57-1.06)$ & 0.106 \\
\hline $\begin{array}{l}\text { Previous attendance at CR before } \\
\text { index event; } n=232\end{array}$ & $11(8.3 \%)$ & $13(13.0 \%)$ & 0.348 & - & - \\
\hline \multicolumn{6}{|l|}{ Barriers subscales; $\mathrm{n}=204$ : } \\
\hline Perceived need/healthcare factors & $2.66 \pm 0.62$ & $1.49 \pm 0.49$ & $<0.001$ & $0.02(0.01-0.06)$ & $<0.001$ \\
\hline Logistic factors & $2.36 \pm 0.91$ & $1.64 \pm 0.77$ & $<0.001$ & $1.79(0.80-3.98)$ & 0.155 \\
\hline Work/time conflicts & $2.22 \pm 0.90$ & $1.75 \pm 0.87$ & $<0.001$ & $1.68(0.86-3.29)$ & 0.128 \\
\hline Co-morbidities/functional status & $2.33 \pm 0.99$ & $1.54 \pm 0.64$ & $<0.001$ & $0.74(0.39-1.39)$ & 0.345 \\
\hline Total CCRBS barriers; $n=205$ & $2.47 \pm 0.58$ & $1.57 \pm 0.55$ & $<0.001$ & - & - \\
\hline
\end{tabular}

Chi-square and independent $t$-tests used to analyse categorical and continuous data, respectively; $\mathrm{n}$ (percent)/mean \pm standard deviation (SD) of complete data detailed for each variable row.

MANOVA of barriers subscales (not including total barriers); attenders $(n=89)$ compared with non-attenders $(n=115)$, Wilks' Lambda $=0.472$, $[F(4,199)=55.588], p<0.001$

+ Multivariate regression analysis based on complete data for 198 responders (113 non-attenders; 85 attenders). Univariate significance taken at $10 \%$ level $(p \leq 0.1)$, excludes total barriers due to correlation with individual barrier scales. Nagelkerke $R^{2}$ of adjusted model $=0.690, p<0.001$.

^Sample size of current smokers too small to enter into multivariate analysis

(CRBS: Shanmugasegaram S, Gagliese L, Oh P, Stewart DE, Brister SJ, Chan V, Grace SL. Psychometric validation of the cardiac rehabilitation barriers scale. Clin Rehabil. 2012; 26(2): 152-164.

$\mathrm{Cl}$ - confidence interval; $\mathrm{CR}$ - cardiac rehabilitation; $\mathrm{MI}$ - myocardial infarction; OR — odds ratio 


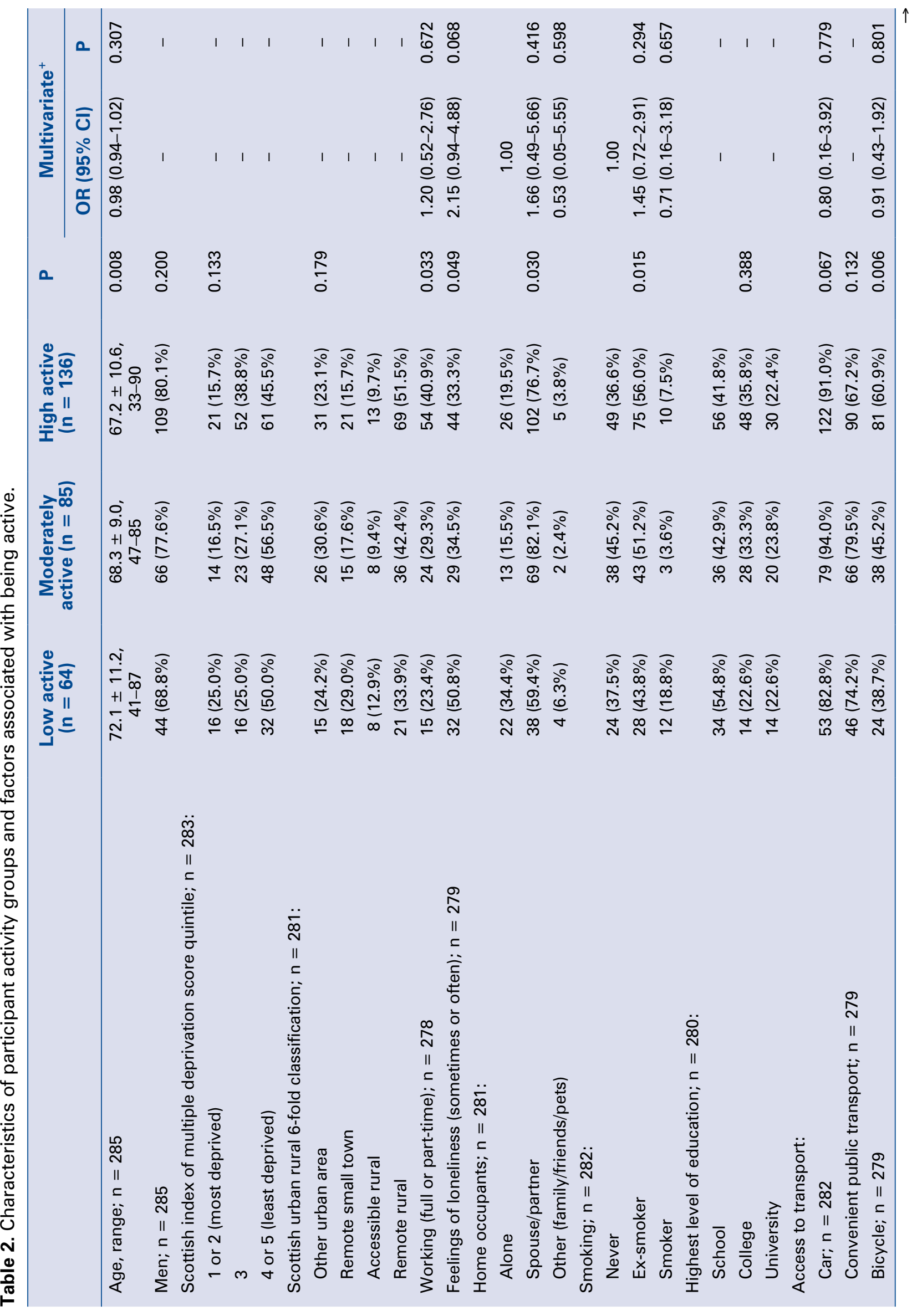




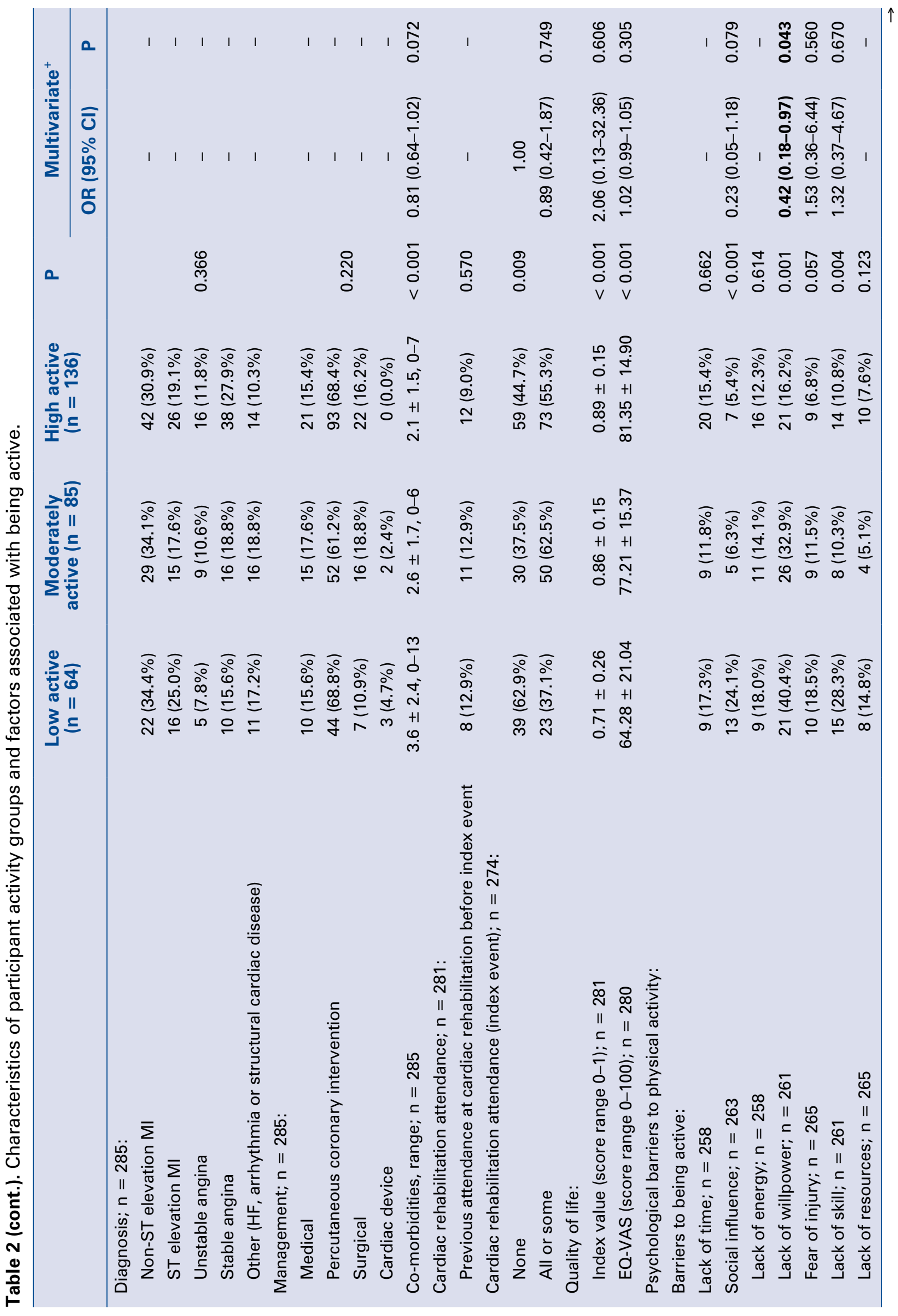




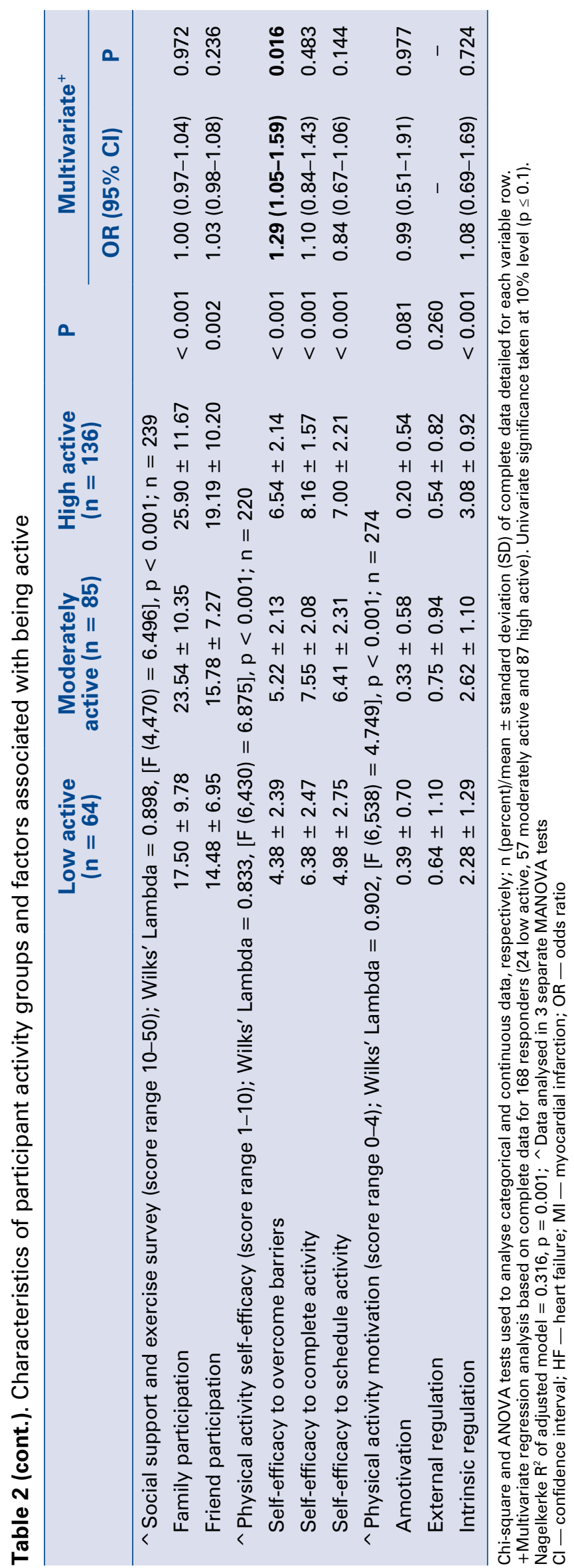

need rehab") could also be targeted through patient education and advice to improve these perceptions.

Distance from classes has been identified as an important barrier in rural populations $[9,10]$. However, in the current study, neither rurality or the logistics barriers subscale (which includes distance, cost and access to transport) showed significant associations with $\mathrm{CR}$ attendance in the fully adjusted model. However, these factors were significant at the univariate level and may merit future research. Study findings may vary due to differences in the geography of Australia and Canada compared to Scotland (degree of rurality), or because there are several CR class sites dispersed across the area considered in this study. This is to ensure the remote rural areas are provided a service, therefore meaning that although the patient's address is considered rural, a CR site may be relatively near to them and distance may not be a barrier to attendance.

\section{Physical activity}

Within the current study, $22.5 \%$ were classed as low active, $29.8 \%$ as moderately active, and $47.7 \%$ as high active. The most important factors associated with PA levels were self-efficacy to overcome barriers to being active and lack of willpower. The positive association between selfefficacy and PA has been extensively reported [28-30]. Although not linked to CR attendance in this study, CR does provide a potential opportunity for patients to develop strategies to overcome barriers to being active, which may support this behaviour in the future. For example, a previous randomised controlled trial compared groupmediated cognitive behavioural interventions (which incorporated training on how to identify and overcome barriers to being active to encourage self-regulation), with a traditional exercise-based CR programme [31]. This study found that those in the cognitive behavioural intervention group showed a greater increase in fitness, and better adherence to an active lifestyle in the long-term, compared with traditional CR. The intervention group also had a greater increase in self-efficacy at post-intervention [31].

Therefore, including such targeted behaviour training to increase self-efficacy and assist patients to identify and overcome barriers to being active, may prove invaluable in CR. In addition to this, other techniques have been shown to increase both self-efficacy and PA, including: action planning, reinforcing efforts towards the desired behaviour, and providing instruction, all of which could be im- 
plemented within CR [32]. Furthermore, national guidelines recommend that psychoeducation and techniques such as goal setting, action planning, and self-monitoring to improve self-efficacy should be considered in CR to improve adherence to the programme, and long-term maintenance of PA [2].

Willpower has previously been identified as a barrier to behaviour change. Lack of willpower was the most commonly reported reason for not adopting desired habits (such as increasing PA) in a study exploring health behaviours in a sample of obese Canadian participants [33]. A lack of willpower was also a more common barrier to behaviour change than work or family responsibilities [34]. Willpower itself has several synonyms and definitions but can be thought of as one's ability to consciously self-regulate behaviour (or self-control). Previous work has suggested that a key component to behaviour change is "perceived behavioural control", which is defined as "the perceived ease or difficulty of performing the behaviour" relating to beliefs about factors that may impact one's ability to perform the desired behaviour [35]. These factors may be internal (e.g. one's willpower) or external (e.g. money required to use facilities to be active). It has been suggested that self-efficacy may contribute to perceived behavioural control, and so the methods above to target self-efficacy, may also be useful in addressing willpower [35].

An association between $\mathrm{CR}$ attendance and future activity levels was not demonstrated in this study. This contrasts with the UK CR audit [6], but is consistent with some other studies [36]. One possible explanation for these contrasting results is that high baseline activity levels before CR may cause some programmes to appear less effective if a higher proportion of patients were active at baseline [6]. Therefore, the benefits may not be apparent at a single site comparison, such as in this study. Furthermore, baseline activity levels in this study are unknown.

This study has several strengths: the respondents were largely representative of the target patient cohort, achieved a $52 \%$ response rate, and the study focused on a remote and rural Scottish population - a group which has been broadly neglected in previous research. However, the use of hospital letters to establish co-morbidity may have led to an underestimation of co-morbidity burden, although this was a consistent approach so no bias would result between patient groups. The self-reported information is subject to both reporter and recall bias.
Future research could aim to address these identified barriers and enhance facilitators. This could involve some of the targeted interventions previously mentioned to improve perceived need, willpower and self-efficacy to overcome barriers to being active in cardiac patients. The effect of any interventions on these factors could be monitored over time and the change in numbers of patients participating in $\mathrm{CR}$ and PA examined with longer follow-up.

\section{Conclusions}

The most important factor identified for CR attendance was lack of perceived need, and for PA the most important factors were self-efficacy to overcome barriers and lack of willpower. The identified factors could potentially be targeted in clinical practice to identify at-risk patients, and strategies implemented to overcome these associations to encourage $\mathrm{CR}$ and $\mathrm{PA}$ participation in these individuals.

\section{Acknowledgments}

The authors are grateful to the staff of the Research, Development and Innovation offices, who assisted in the distribution and collection of questionnaires, and the Cardiac Rehabilitation staff. The authors would like to thank all patients involved in this study.

Funding: DC was funded by Highlands and Islands Enterprise (project number HMS 9353763).

\section{Conflict of interest: None declared}

\section{References}

1. Moran AE, Forouzanfar MH, Roth GA, et al. Temporal trends in ischemic heart disease mortality in 21 world regions, 1980 to 2010: the Global Burden of Disease 2010 study. Circulation. 2014; 129(14): 1483-1492, doi: 10.1161/CIRCULATIONAHA.113.004042, indexed in Pubmed: 24573352.

2. Scottish Intercollegiate Guidelines Network (SIGN). Cardiac rehabilitation, a national clinical guideline (SIGN 150) [Internet]. SIGN; 2017. http://www.sign.ac.uk/assets/sign150.pdf (accessed 28/03/2018).

3. Anderson L, Oldridge N, Thompson DR, et al. Exercise-based cardiac rehabilitation for coronary heart disease. Cochrane Database Syst Rev. 2016; 67(1): CD001800-12, doi: 10.1002/14651858. CD001800.pub3, indexed in Pubmed: 26730878.

4. Department of Health, Physical Activity, Health Improvement and Protection. Start Active, Stay Active: A report on physical activity from the four home countries' Chief Medical Officers [Internet]. Department of Health, Physical Activity, Health Improvement and Protection; 2011. www.dh.gov.uk/en/Publica- 
tionsandstatistics/Publications/PublicationsPolicyAndGuidance/ DH_128209 (accessed 22/12/18).

5. Townsend N, Wickramasinghe K, Williams J, et al. Physical activity statistics 2015 [Internet]. The British Heart Foundation; 2015. https://www.bhf.org.uk/publications/statistics/physicalactivity-statistics-2015 (accessed 28/03/18).

6. Doherty P, Petre C, Onion N, et al. The National Audit of Cardiac Rehabilitation Annual Statistical Report [Internet]. The British Heart Foundation; 2018. https://www.bhf.org.uk/publications/statistics/national-audit-of-cardiac-rehabilitation-annual-statisticalreport-2017 (accessed 28/03/18).

7. Daly J, Sindone AP, Thompson DR, et al. Barriers to participation in and adherence to cardiac rehabilitation programs: a critical literature review. Prog Cardiovasc Nurs. 2002; 17(1): 8-17, indexed in Pubmed: 11872976.

8. Neubeck L, Freedman SB, Clark AM, et al. Participating in cardiac rehabilitation: a systematic review and meta-synthesis of qualitative data. Eur J Prev Cardiol. 2012; 19(3): 494-503, doi: 10.1177/1741826711409326, indexed in Pubmed: 22779092.

9. De Angelis C, Bunker S, Schoo A. Exploring the barriers and enablers to attendance at rural cardiac rehabilitation programs. Aust J Rural Health. 2008; 16(3): 137-142, doi: 10.1111/j.14401584.2008.00963.x, indexed in Pubmed: 18471183.

10. Shanmugasegaram S, Oh P, Reid RD, et al. Cardiac rehabilitation barriers by rurality and socioeconomic status: a cross-sectional study. Int J Equity Health. 2013; 12: 72, doi: 10.1186/1475-927612-72, indexed in Pubmed: 23985017.

11. Lafortune L, Martin S, Kelly S, et al. Barriers and facilitators to the uptake and maintenance of healthy behaviours by people at mid-life: a rapid systematic review. PLoS One. 2016; 11(1): e0145074, doi: 10.1371/journal.pone.0145074, indexed in Pubmed: 26815199.

12. The Scottish Government. Scottish Government Urban/Rural Classification 2013-2014 [Internet]. The Scottish Government; 2014. http://www.gov.scot/Resource/0046/00464780.pdf (accessed 28/03/18).

13. The EuroQol Group. EuroQol - a new facility for the measurement of health-related quality of life. Health Policy. 1990; 16(3): 199-208, doi: 10.1016/0168-8510(90)90421-9.

14. Devlin NJ, Shah KK, Feng Y, et al. Valuing health-related quality of life: An EQ-5D-5L value set for England. Health Econ. 2018; 27(1): 7-22, doi: 10.1002/hec.3564, indexed in Pubmed: 28833869.

15. Shanmugasegaram S, Gagliese L, Oh P, et al. Psychometric validation of the cardiac rehabilitation barriers scale. Clin Rehabil. 2012; 26(2): 152-164, doi: 10.1177/0269215511410579, indexed in Pubmed: 21937522.

16. Craig CL, Marshall AL, Sjöström M, et al. International physical activity questionnaire: 12-country reliability and validity. Med Sci Sports Exerc. 2003; 35(8): 1381-1395, doi: 10.1249/01. MSS.0000078924.61453.FB, indexed in Pubmed: 12900694.

17. The International Physical Activity Questionnaire (IPAQ) Group. Guidelines for the data processing and analysis of the International Physical Activity Questionnaire (IPAQ) - Short and Long Forms. The IPAQ Group; 2005. https://sites.google.com/site/ theipaq/home (accessed 28/03/2018).

18. U.S. Department of Health and Human Services, Public Health Service, Centers for Disease Control and Prevention, National Center for Chronic Disease Prevention and Health Promotion, Division of Nutrition and Physical Activity. Promoting Physical Activity: A Guide for Community Action.

19. Sallis JF, Grossman RM, Pinski RB, et al. The development of scales to measure social support for diet and exercise behaviors. Prev Med. 1987; 16(6): 825-836, indexed in Pubmed: 3432232.
20. Anderson AS, Caswell S, Wells M, et al. "It makes you feel so full of life" LiveWell, a feasibility study of a personalised lifestyle programme for colorectal cancer survivors. Support Care Cancer. 2010; 18(4): 409-415, doi: 10.1007/s00520-009-0677-4, indexed in Pubmed: 19554354.

21. Markland D, Tobin V. A Modification to the Behavioural Regulation in Exercise Questionnaire to Include an Assessment of Amotivation. J Sport Exerc Psychol. 2004; 26(2): 191-196, doi: 10.1123/jsep.26.2.191.

22. Wilson P, Rodgers W, Loitz C, et al. "It's Who I Am... Really!' The Importance of Integrated Regulation in Exercise Contexts1. J Appl Biobehav Res. 2007; 11(2): 79-104, doi: 10.1111/j.17519861.2006.tb00021.x.

23. The Scottish Government. Introducing The Scottish Index of Multiple Deprivation 2016 [Internet]. The Scottish Government; 2016. http:// www.gov.scot/Resource/0050/00504809.pdf (accessed 28/03/18).

24. Grace SL, Gravely-Witte S, Kayaniyil S, et al. A multisite examination of sex differences in cardiac rehabilitation barriers by participation status. J Womens Health (Larchmt). 2009; 18(2): 209-216, doi: 10.1089/jwh.2007.0753, indexed in Pubmed: 19183092.

25. Grace SL, Shanmugasegaram S, Gravely-Witte S, et al. Barriers to cardiac rehabilitation: does age make a difference? J Cardiopulm Rehabil Prev. 2009; 29(3): 183-187, doi: 10.1097/ HCR.0b013e3181a3333c, indexed in Pubmed: 19471138.

26. Dolansky MA, Moore SM, Visovsky C. Older adults' views of cardiac rehabilitation program: is it time to reinvent? J Gerontol Nurs. 2006; 32(2): 37-44, indexed in Pubmed: 16502760.

27. Ghisi GLM, Polyzotis P, Oh P, et al. Physician factors affecting cardiac rehabilitation referral and patient enrollment: a systematic review. Clin Cardiol. 2013; 36(6): 323-335, doi: 10.1002/ clc.22126, indexed in Pubmed: 23640785.

28. McAuley E, Blissmer B. Self-efficacy determinants and consequences of physical activity. Exerc Sport Sci Rev. 2000; 28(2): 85-88.

29. McAuley E, Courneya KS, Lettunich J. Effects of acute and longterm exercise on self-efficacy responses in sedentary, middleaged males and females. Gerontologist. 1991; 31(4): 534-542, doi: 10.1093/geront/31.4.534, indexed in Pubmed: 1894158.

30. McAuley E, Lox C, Duncan TE. Long-term maintenance of exercise, self-efficacy, and physiological change in older adults. J Gerontol. 1993; 48(4): P218-P224, indexed in Pubmed: 8315239.

31. Rejeski WJ, Brawley LR, Ambrosius WT, et al. Older adults with chronic disease: benefits of group-mediated counseling in the promotion of physically active lifestyles. Health Psychol. 2003; 22(4): 414-423, indexed in Pubmed: 12940398.

32. Williams SL, French DP. What are the most effective intervention techniques for changing physical activity self-efficacy and physical activity behaviour--and are they the same? Health Educ Res. 2011; 26(2): 308-322, doi: 10.1093/her/cyr005, indexed in Pubmed: 21321008.

33. Bastin A, Romain AJ, Marleau J, et al. Health behaviours, intentions and barriers to change among obesity classes I, II and III. Clin Obes. 2019; 9(1): e12287, doi: 10.1111/cob.12287, indexed in Pubmed: 30458581.

34. Haberman C, Brauer P, Dwyer JJ, et al. Self-reported health behaviour change in adults: analysis of the Canadian Community Health Survey 4.1. Chronic Dis Inj Can. 2014; 34(4): 248-255, indexed in Pubmed: 25408184.

35. Ajzen I. Perceived behavioral control, self-efficacy, locus of control, and the theory of planned behavior. J Appl Soc Psychol. 2002; 32(4): 665-683, doi: 10.1111/j.1559-1816.2002.tb00236.x.

36. West RR, Jones DA, Henderson AH. Rehabilitation after myocardial infarction trial (RAMIT): multi-centre randomised controlled trial of comprehensive cardiac rehabilitation in patients following acute myocardial infarction. Heart. 2012; 98(8): 637-644, doi: 10.1136/heartjnl-2011-300302, indexed in Pubmed: 22194152. 